\title{
RECLAMATION OF USED LUBRICATING OILS
}

No special apparatus for the reclamation of used lubricating oils by means of steam has been developed by this Bureau, and it is believed that apoutus of this kind should be in any case adapted to special requirements, such as quantity of oil at hand and specifications for the recovered product.

Most oils used in erank cases of internal combustion engines can be reclaimed to a sufficient degree to warrant the installation of apparatus necessary, if the quantity of used oils to be salvaged is considerable.

The recovery of these oils consists of:

1. Separation of free carbon and metalif sediment;

2. Neutralization of acid compounds formed through use;

3. Washing of oils to remove alkali;

4. Separation by distillation of light hydrocarbons absorbed by the oil from the fuel or generated in it, due to cracking;

5. If necessary, filtration of the oil to remove colloidal matter;

6. Blending to physical properties desired.

The sequence of these processes can be varied, or it is possible to combine two or more of them in one separation.

The separation of solid particles, both carbon and metallic, can be accomplished by allowing the oil to settle 


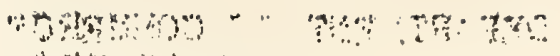

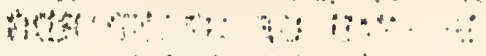

$$
\begin{aligned}
& \because \because \because \because \because \cdots
\end{aligned}
$$

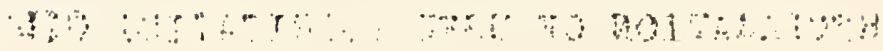

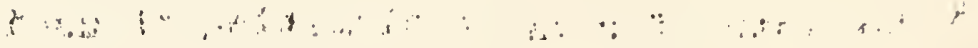

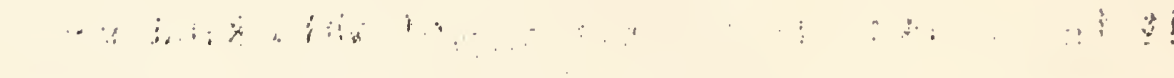

$$
\begin{aligned}
& \therefore
\end{aligned}
$$

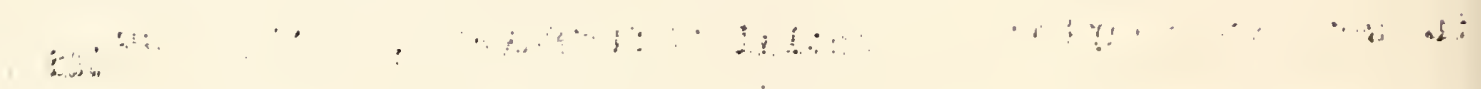

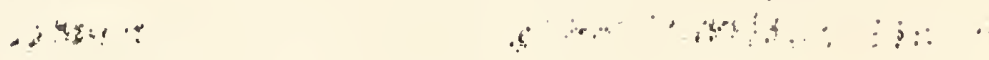

$$
\begin{aligned}
& \therefore:-\because \vdots \vdots
\end{aligned}
$$

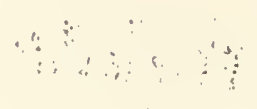

$$
\begin{aligned}
& \because \cdot 3 \\
& \therefore \because \\
& \ddot{n}
\end{aligned}
$$

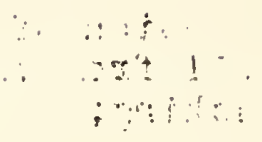

$$
\begin{aligned}
& \because \vdots \div+\div \\
& \text { i. . . } \\
& \therefore \\
& \therefore \\
& \text { ? } \\
& \because \because i
\end{aligned}
$$


for at least twenty-four hours in a tank designed so that the pure oil can be easily decanted. It is advantageous to provide a vertical tank, the height of which should be about three times its diameter, with drainage taps placed at different heights along one side and also one on the bottom for cleaning. By opening successive taps, starting wi th the highest one, the oil free of sediment can be drawn off, or a single tap at the top can be used and the oil displaced by admitting water at the bottom. If quickar separation is desired, any commercial centrifuge or separator can be adopted for the purpose.

The neutralization of the oil is done by caustic soda or soda ash in an agitator. This consists of a cylindrical vessel with a height of about four times its dianeter and a conical bottom, at the center of which is attached a pipe connection for the admission of steam or vater. About one pound of sodium hydroxide, preferably in powdered form; or in small lumps, should be added to each five gallons of oil, and this amount may be increased proportionately if the oil to be reclaimed contains fatty oils. The agitator should not be filled more than half with oil to be reclaimed and after addition of the alkali, the steam turned on to a degrse to cause vignrous agitation. This operation should last about one-half hour, after which the oij. should be allo:sed to 6001 and settle for another trenty-four hours. After this, cold water is admitted through the bottom of the cone in a stream not too strong to cause turbulence, and this raises the separated oil to the top of the agitator, from 

where it can be run out through a suitaole opening. Some oil may be recovered from the soda sludge left in the agitator by heating to the boiling point of water for ten minutes and allowing to settle.

If it should be found necessary, the oil thus freed from acid may be washed several times with water to remove alkali, and then transferred into a horizontal direct fire still provided vith an open steam coil. As soon as distillation begins, the steam should be turned on full and the distillation carried far enough to bring the oil back to a desired slash point. With the average internal combustion. engine lubricants, this should be around 380 to $390^{\circ} \mathrm{F}$ in case of paraffin base oijs, and about 330 to $340^{\circ} \mathrm{F}$ with asphaltic base oils. When this point has been reached, the fire is arawn and the current of steam kept up until the oil cools to aboid $250^{\circ} \mathrm{F}$. Then the steam is shut of $f$ and the oil drawn out after cooling.

If the oil is likely to contain a large quantity of colloidal carbonaceous matter, it snould be subjected to filtration through Fuller's earth and then tested for its prisical properties in the usual way. If its viscosity is below the one of the original oil, it should be increased by biering with cylinder stock of 150 viscosity at $212^{\circ} \mathrm{F}$; whereas, if the viscosity is higher than desired, scme spindle stock of 180 viscosity at $100^{\circ}$ should be added. The blending should be cone at a heat of about $150^{\circ} \mathrm{F}$, by thoroughly mixing for about ten to fifteen minutes. 

It has been found that oils treated in this way are at least as good as new oils and in some cases better, for those compounds which easily decorrpose during service have been $r$ moved. 


$$
\therefore
$$

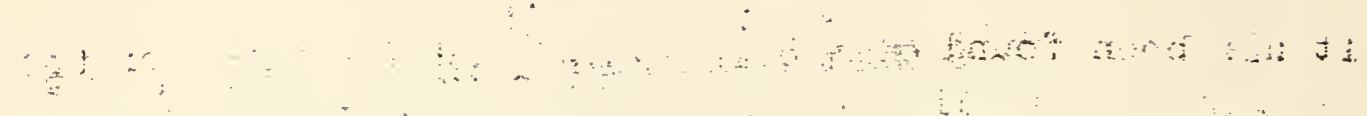

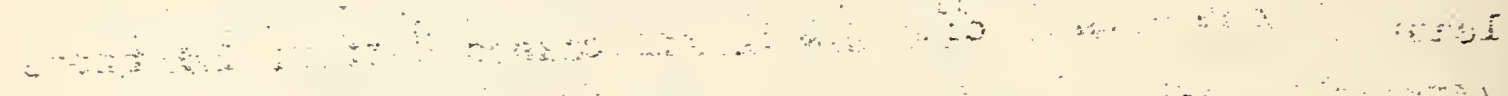

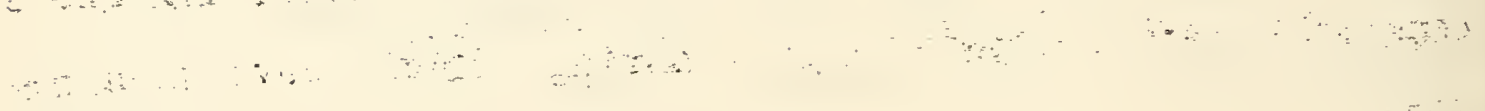


. 
